\title{
THEORETICAL STUDY OF THERMODYNAMIC PROPERTIES OF Cu-Pb LIQUID ALLOYS AT DIFFERENT TEMPERATURE BY OPTIMIZATION METHOD
}

Ganesh Kumar Shrestha, Bijay Kumar Singh, Indu Shekhar Jha and Ishwar Koirala

Journal of Institute of Science and Technology

Volume 22, Issue 1, July 2017

ISSN: 2469-9062 (print), 2467-9240 (e)

Editors:

Prof. Dr. Kumar Sapkota

Prof. Dr. Armila Rajbhandari

Assoc. Prof. Dr. Gopi Chandra Kaphle

JIST, 22 (1): 25-33 (2017)

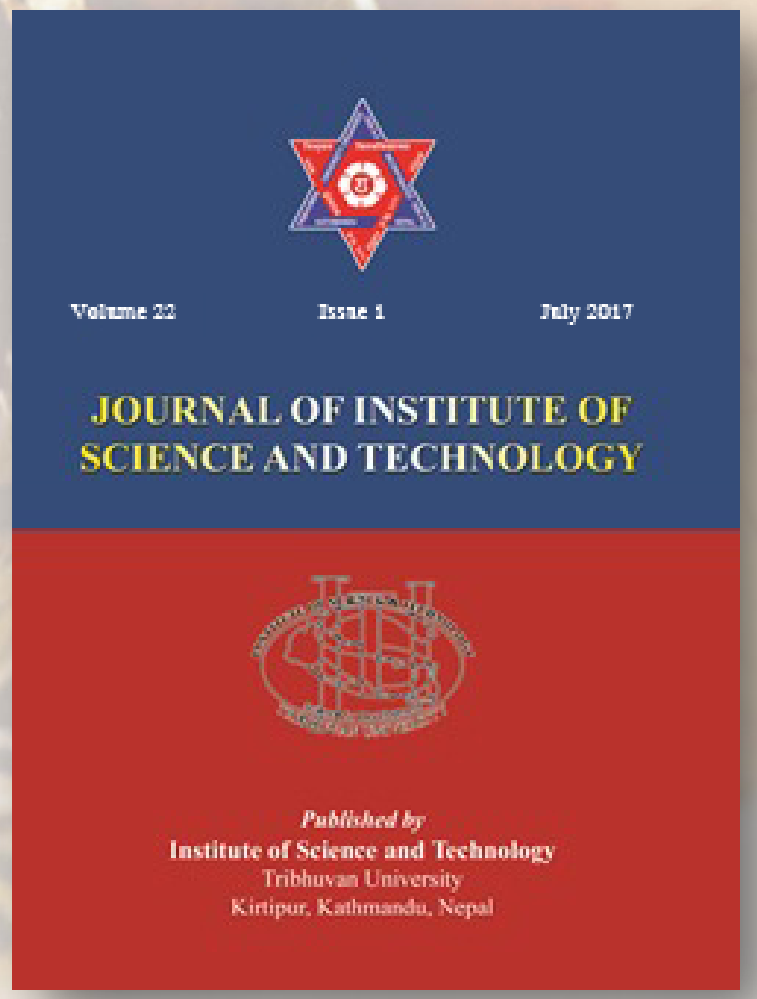

Published by:

Institute of Science and Technology

Tribhuvan University

Kirtipur, Kathmandu, Nepal 


\title{
THEORETICAL STUDY OF THERMODYNAMIC PROPERTIES OF Cu-Pb LIQUID ALLOYS AT DIFFERENT TEMPERATURE BY OPTIMIZATION METHOD
}

\author{
Ganesh Kumar Shrestha ${ }^{1,2}$, Bijay Kumar Singh ${ }^{1}$, Indu Shekhar Jha ${ }^{3}$, and Ishwar Koirala ${ }^{4, *}$ \\ ${ }^{1}$ University Department of Physics, T. M. Bhagalpur University, Bhagalpur, India \\ ${ }^{2}$ Pulchowk Campus, IOE, Tribhuvan University, Lalitpur, Nepal \\ ${ }^{3}$ M. M. A. M. Campus, Tribhuvan University, Biratnagar, Nepal \\ ${ }^{4}$ Central Department of Physics, Tribhuvan University, Kirtipur, Nepal \\ ${ }^{*}$ Corresponding E-mail: ishwar_koirala@yahoo.com
}

\begin{abstract}
A theoretical assessment on thermodynamic properties and concentration fluctuations of $\mathrm{Cu}-\mathrm{Pb}$ liquid alloys at a specified temperature has been made by using the fitted values for size ratio $(\Omega)$ and order energy parameter $(\mathrm{W})$ of the alloys in Quasi-Lattice Theory where the combined effect of size ratio, entropic and enthalpic effect is considered. The order energy parameter $(\mathrm{W})$ of the alloys is temperature dependent and its value at the required temperature has been determined by using the value of order energy parameter at the given temperature and temperature derivative of order energy parameter $\left(\frac{d W}{d T}\right)$. The values of $\mathrm{W}$ at different temperatures have been used to determine the free energy of mixing of the alloys at different temperatures which are then used for the optimization procedure in order to calculate the corresponding values of partial excess free energy of mixing and activity of the constituents involved in the alloy at different temperatures. These parameters have been used to predict the concentration fluctuations in long wavelength limit $\left(\mathrm{S}_{\mathrm{cc}}(0)\right)$ at different temperatures in the entire range of concentration.
\end{abstract}

Keywords: Optimization procedure, Order energy parameter, Partial excess free energy of mixing, Size ratio, Liquid alloys.

\section{INTRODUCTION}

Investigations on the thermodynamic and structural properties of the alloys in liquid state are very essential to study the alloying behavior of the alloys. In order to achieve this goal, metal physicists, chemists and metallurgists have been working on several models (Flory, 1942; Alonso \& March, 1982; Bhatia \& Singh, 1989; Prasad et al., 1989; Young, 1992; Akinlade et al., 2000; Adhikari et al., 2010; Koirala et al., 2013, 2014; Jha et al., 2014; Singh et al., 2014a, 2014b) to understand the mixing properties of binary liquid alloys for preparing desired alloys.

Copper being one of the most useful metals in our life because of its extraordinary corrosion resistance property is widely used in our daily-life mostly as a pure metal. Since it is a little soft metal, its hardness can be increased by making its alloys which have huge commercial applications because of their good electrical and mechanical properties along with high corrosion resistance. Though there are numerous copper alloys present in the market, we are focusing here on $\mathrm{Cu}-\mathrm{Pb}$ alloys for the discussion of its various properties in molten state which may be useful in manufacturing the Triboelements such as bearings, cutting tools, gears, brakes, and seals.

In modern technology, we have many mechanical equipments and machines based on moving or sliding mechanism which require high performance materials to achieve the reliability, accuracy and life of mechanical systems. It indicates that the Tribo-elements should have appropriate friction and wear properties. In this respect, lead can be used as a solid lubricant which reduces friction between sliding surfaces significantly (Buchanan et al., 1991).

$\mathrm{Cu}-\mathrm{Pb}$ alloys can also be used for the materials of bearing because of their low coefficient of friction and relatively high loads-bearing capacity. They have special composite microstructures consisting of a hard matrix with dispersions of soft phases 
which act as lubricants to reduce the friction on the sheared surface layer and the hard matrix phase is strong enough to support relatively high loads (Cui et al., 2007). Further, appropriate alloying element like $\mathrm{Cr}$ can be added to $\mathrm{Cu}-\mathrm{Pb}$ alloys for improving wear properties. However, there is a limitation to dissolve higher quantities of lead because of existence of liquid miscibility gap which can be studied by changing the solidification conditions (Mudry, 1996).

In the present work, quasi-lattice theory by considering the combined effect of size ratio, entropic and enthalpic effect have been used to explain the various thermodynamic properties and concentration fluctuations of $\mathrm{Cu}-\mathrm{Pb}$ liquid alloys at a specified temperature $(\mathrm{T}=1473 \mathrm{~K})$ in section- 2 . These thermodynamic properties and concentration fluctuations of $\mathrm{Cu}-\mathrm{Pb}$ liquid alloys at the temperature $\mathrm{T}=1473 \mathrm{~K}$ have been calculated and compared with their corresponding experimental values in section-3. Furthermore, we have used the optimization procedure to compute the excess free energy of mixing at different temperatures and hence optimized coefficients of $\mathrm{Cu}-\mathrm{Pb}$ liquid alloys which are then used to determine the partial excess free energy of mixing as well as activity of both the components and hence concentration fluctuations in long wave-length limit $\left(\mathrm{S}_{\mathrm{cc}}(0)\right)$ at different temperatures in the entire range of concentration in section-4.

\section{FORMALISM}

\section{Free energy of mixing $\left(G_{M}\right)$}

Let us consider one mole binary alloys $\mathrm{X}-\mathrm{Y}$ in molten state such that the liquid mixture contains one of the constituent $\mathrm{X}(\equiv \mathrm{Cu})$ with concentration $\mathrm{c}_{\mathrm{X}}=\mathrm{c}$ so that $\mathrm{cN}=\mathrm{N}_{\mathrm{X}}$ (No. of constituent $\mathrm{X}$ ) and another constituent $\mathrm{Y}(\equiv \mathrm{Pb})$ with concentration $\mathrm{c}_{\mathrm{Y}}=(1-\mathrm{c})$ so that $(1-\mathrm{c}) \mathrm{N}=\mathrm{N}_{\mathrm{Y}}$ (No. of constituent $\mathrm{Y}$ ) where $\mathrm{N}$ represents Avogadro's Number. If we consider the constituent atoms $\mathrm{X}$ and $\mathrm{Y}$ of the binary mixture with different shape and size, and entropic as well as enthalpic effect of the binary mixture $\left(\mathrm{H}_{M} \neq 0\right)$, then the Quasi- Lattice Theory (QLT) of liquid mixture at a temperature (T) as explained by Guggenheim (1952) in the limit Z (the coordination number) $\rightarrow \infty$ gives an expression for free energy of mixing $\left(\mathrm{G}_{\mathrm{M}}\right)$ as

$G_{M}=R T[(1-c) \ln \varphi+\mathrm{c} \ln (1-\varphi)+\mathrm{c} \varphi \mathrm{W}]$

where $\mathrm{R}$ is the molar gas constant and $\Omega$ $\left(=\frac{\Omega_{Y}}{\Omega_{X}} ; \Omega_{Y}>\Omega_{X}\right)$ is the size ratio and
Here, $\varphi=\frac{\Omega(1-c)}{c+\Omega(1-c)}$

And, $\mathrm{W}=\alpha_{\mathrm{X}}\left(\frac{}{\mathrm{K}_{\mathrm{B}} \mathrm{T}}\right)$

which represents order energy parameter, where $\alpha_{X}$ is the number of a group of lattice sites, occupying by $\mathrm{N}_{\mathrm{X}}$ atoms of the constituent $\mathrm{X}, \mathrm{K}_{\mathrm{B}}$ is the Boltzmann constant and $\omega$ is the interchange energy, which is represented by

$\omega=\left(\epsilon_{X Y}-\frac{\epsilon_{X X}+\epsilon_{Y Y}}{2}\right)$

Here, $\epsilon_{\mathrm{ij}}(\mathrm{i} ; \mathrm{j}=\mathrm{X} ; \mathrm{Y})$ is $\mathrm{i}-\mathrm{j}$ bond strength.

\section{Activity (a)}

From the standard thermodynamic relation, the activity of a constituent $i$ of the binary alloy is represented by

$\mathrm{RT} \ln \mathrm{a}_{\mathrm{i}}=G_{M}+c_{j}\left(\frac{\partial \mathrm{G}_{\mathrm{M}}}{\partial \mathrm{c}_{\mathrm{i}}}\right)$

where $a_{i}$ and $c_{j}$ are the activity and concentration of component $\mathrm{i}$ and $\mathrm{j}$ respectively $(\mathrm{i} ; \mathrm{j} \equiv \mathrm{X} ; \mathrm{Y}$ ).

On solving expression (5) with the help of expression (1), we obtain

$\ln \mathrm{a}_{\mathrm{X}}=\ln (1-\varphi)+\varphi\left\{\frac{(\Omega-1)}{\Omega}\right\}+\varphi^{2} \mathrm{~W}$

And,

$\ln \mathrm{a}_{\mathrm{Y}}=\ln \varphi-(1-\varphi)(\Omega-1)+W \Omega(1-\varphi)^{2}$

where $a_{X}$ and $a_{Y}$ are the activity of the constituent $X$ and $\mathrm{Y}$ respectively.

\section{Concentration Fluctuations in Long Wave- length Limit $\left(\mathbf{S}_{\mathrm{cc}}(\mathbf{0})\right)$}

The concentration fluctuations in long wavelength limit of a binary liquid alloy $\left(\mathrm{S}_{\mathrm{cc}}(0)\right)$ at a temperature (T) as defined by Bhatia and Thornton (1971) is given by

$S_{c c}(0)=\frac{R T}{\left(\frac{\partial^{2} \mathrm{G} M}{\partial c^{2}}\right)_{\mathrm{P}, \mathrm{N}, \mathrm{T}}}$

On solving expression (8) with the help of expression (1), we obtain

$S_{c c}(0)=\frac{c(1-c)}{1-c(1-c)\{g(\Omega, W)\}}$ 
with $g(\Omega, W)=\frac{2 \Omega^{2} W-(\Omega-1)^{2}\{c+\Omega(1-c)\}}{\{c+\Omega(1-c)\}^{3}}$

Also, the concentration fluctuations of a binary liquid alloy $\mathrm{X}-\mathrm{Y}$ in long wavelength limit can be determined from the experimental value of activity, by using the relation.

$S_{c c}(0)=\mathrm{c}_{\mathrm{i}} \mathrm{a}_{\mathrm{j}}\left(\frac{\partial \mathrm{a}_{\mathrm{j}}}{\partial \mathrm{c}_{\mathrm{j}}}\right)_{\mathrm{T}, \mathrm{P}}^{-1}$

where $c_{i}$ and $a_{j}$ are the concentration and activity of component $\mathrm{i}$, and $\mathrm{j}$ respectively $(\mathrm{i} ; \mathrm{j} \equiv \mathrm{X} ; \mathrm{Y}$ ).

So, the expression (11) represents experimental value of concentration fluctuations of binary liquid alloys $\mathrm{X}-\mathrm{Y}$ in long wavelength limit.

Again, the ideal value of concentration fluctuations of binary liquid alloys is obtained from the relation

$s_{c c}^{i d}(0)=c(1-\mathrm{c})$

The concentration fluctuations in long wavelength limit $\left(S_{c c}(0)\right)$ is the microscopic property of binary liquid alloys which gives the idea to understand the nature of the alloys. The mixing behavior, i.e. the nature of interaction of constituent atoms of binary liquid alloys can be analyzed with the help of deviation of $S_{c c}(0)$ from $S_{c c}^{i d}(0)$. For the given composition, we expect the binary liquid alloys of ordering nature, if $S_{c c}(0)<s_{c c}^{i d}(0)$, but segregating nature, if $S_{c c}(0)>s_{c c}^{i d}(0)$. Various other properties of binary liquid alloys like excess stability function, diffusion coefficient, etc. can be explained with the help of values of concentration fluctuations of the alloys in long wavelength limit.

\section{Entropy of Mixing $\left(\mathbf{S}_{\mathbf{M}}\right)$}

From the standard thermodynamic relation, the entropy of mixing for a binary liquid alloys is given by

$$
S_{M}=-\frac{\partial\left(G_{M}\right)}{\partial T}
$$

On solving this equation by using expression (1), we obtain

$$
\begin{aligned}
& \frac{S_{M}}{R}=-[(1-c) \ln \varphi+c \ln (1-\varphi)+c \varphi(W+ \\
& \left.\left.T \frac{d W}{d T}\right)\right]
\end{aligned}
$$

\section{Heat of Mixing $\left(\mathrm{H}_{\mathrm{M}}\right)$}

From the standard thermodynamic relation, the Heat of mixing for a binary liquid alloys is given by
$\frac{H_{M}}{R T}=\frac{G_{M}}{R T}+\frac{S_{M}}{R}=-c \varphi T\left(\frac{d W}{d T}\right)$

\section{Optimization of Free energy of mixing; Activity; Concentration fluctuations}

Optimization procedure is the thermodynamic explanation which uses statistical thermodynamics and polynomial expressions. It has good capability to obtain a consistent set of model parameters analytically which gives the knowledge to extrapolate into temperature and concentration region where the direct experimental data are unavailable. The least-square method is used in this process to estimate the adjustable coefficients.

On using a power-series law whose coefficients are $\mathrm{A}, \mathrm{B}, \mathrm{C}, \mathrm{D}, \mathrm{E}, \ldots \ldots$ (let), the standard thermodynamic relation, $\mathrm{G}=\mathrm{H}-\mathrm{TS}$, provides the temperature $(\mathrm{T}$ ) dependent free energy (Singh \& Sommer 1997) as

$G=A+B T+C T \ln T+D T^{2}+\ldots \ldots \ldots$

Again, the concentration dependence of excess free energy of mixing is given by Redlich-Kister polynomial equation as

$G_{M}^{X S}(c, T)=c(1-c) \sum_{l=0}^{m} K_{l}(T)[2 c-1]^{\iota}$

with $K_{l}(T)=A_{l}+B_{l} T+C_{l} T \ln T+D_{l} T^{2}+\ldots \ldots$

The coefficients $K_{l}$ depend upon the temperatures same as that of $G$, represented in equation (15). The least-square method is used to obtain the parameters involved in expression (16), which requires the excess free energy of mixing $\left(G_{M}^{X S}\right)$ of the binary liquid alloys at different temperatures and they are determined by the relation:

$$
\begin{aligned}
G_{M}^{X S} & =G_{M}-G_{M}^{I d} \\
& =G_{M}-R T[c \ln c+(1-c) \ln (1-\mathrm{c})]
\end{aligned}
$$

So, we need the values of free energy of mixing $\left(\mathrm{G}_{\mathrm{M}}\right)$ of the binary liquid alloys at different temperatures which can be computed from expression (1) by knowing the values of size ratio $(\Omega)$ and order energy parameter $(\mathrm{W})$ of the alloy at different temperatures. It is obvious that the change in temperature may change the size ratio of $\mathrm{Cu}-\mathrm{Pb}$ liquid alloy but the calculation shows that this change in size ratio does not change the values of other thermodynamic properties and concentration fluctuations in long wavelength of the alloys in appreciable amount. Thus, the fitted value of size 
ratio $(\Omega)$ for $\mathrm{Cu}-\mathrm{Pb}$ liquid alloys at all temperatures is taken as constant (i.e. $\Omega=1.31$ ) in the entire calculation of thermodynamic and other properties.

Further, the order energy parameter at required temperature $T_{k}$ is obtained from the relation

$W\left(T_{k}\right)=W(T)+\frac{d W}{d T}\left(\mathrm{~T}_{\mathrm{K}}-\mathrm{T}\right)$

where $\mathrm{W}(\mathrm{T})$ is the order energy parameter at the given temperature $\mathrm{T}$ and $\frac{\mathrm{dW}}{\mathrm{dT}}$ represents temperature derivative of order energy parameter for the given liquid alloy.

\section{RESULTS AND DISCUSSION}

The experimental values of free energy of mixing $\left(\mathrm{G}_{\mathrm{M}}\right)$, activity of both the constituents $\left(\mathrm{a}_{\mathrm{i}}\right)(\mathrm{i} \equiv \mathrm{Cu}$; $\mathrm{Pb}$ ) and concentration fluctuations in long wavelength limit $\left\{S_{c c}(0)\right\}$ of $\mathrm{Cu}-\mathrm{Pb}$ binary liquid alloys at the temperature $(\mathrm{T}=1473 \mathrm{~K})$ have been used to determine the best fitted values of two parameters - size ratio $(\Omega)$ and order energy parameter (W) of the alloys. The fitted values of size ratio $(\Omega)$ and order energy parameter $(\mathrm{W})$ of the alloy have been estimated with the help of expressions (1), (6), (7), and (9) to reproduce simultaneously an overall fit for the theoretical and experimental values of free energy of mixing $\left(G_{M}\right)$, activity $\left(\mathrm{a}_{\mathrm{i}}\right)$ of the component $\mathrm{i}(\mathrm{i}=\mathrm{Cu} ; \mathrm{Pb})$ and concentration fluctuations in long wavelength limit $\left\{S_{c} c_{c}(0)\right\}$ of $\mathrm{Cu}-\mathrm{Pb}$ liquid alloys at $1473 \mathrm{~K}$ in the entire concentration ranging from 0.1 to 0.9 .

The best fit value of size ratio $(\Omega)$ for $\mathrm{Cu}-\mathrm{Pb}$ liquid alloys at $1473 \mathrm{~K}$ is found to be 1.31 and of order energy parameter $(\mathrm{W})$ for $\mathrm{Cu}-\mathrm{Pb}$ liquid alloys at $1473 \mathrm{~K}$ is found to be 1.52 . By taking the fitted values of $\Omega=1.31$ and $\mathrm{W}=1.52$, the theoretical values of $\mathrm{G}_{\mathrm{M}} / \mathrm{RT}$ for $\mathrm{Cu}-\mathrm{Pb}$ liquid alloys at $1473 \mathrm{~K}$ in the entire concentration range have been computed by using expression (1) while the experimental values of $\mathrm{G}_{\mathrm{M}} / \mathrm{RT}$ for $\mathrm{Cu}-\mathrm{Pb}$ liquid alloys at $1473 \mathrm{~K}$ in the entire concentration range have been computed by using experimental data (Hultren et al. 1973). The theoretical and experimental values of $\mathrm{G}_{\mathrm{M}} / \mathrm{RT}$ for $\mathrm{Cu}-\mathrm{Pb}$ liquid alloys at $1473 \mathrm{~K}$ in the entire concentration range are compared by plotting their graphs against the concentration of $\mathrm{Cu}$ as shown in Fig. 1., which are in good agreement. The experimental value of $\mathrm{G}_{\mathrm{M}} / \mathrm{RT}$ at $1473 \mathrm{~K}$ is minimum at the concentration, $\mathrm{c}=0.4$, which is found to be 0.274474 and the theoretical value of $\mathrm{G}_{\mathrm{M}} / \mathrm{RT}$ at $1473 \mathrm{~K}$ is minimum at the same concentration, $\mathrm{c}=0.4$ which is found to be -0.278641 .

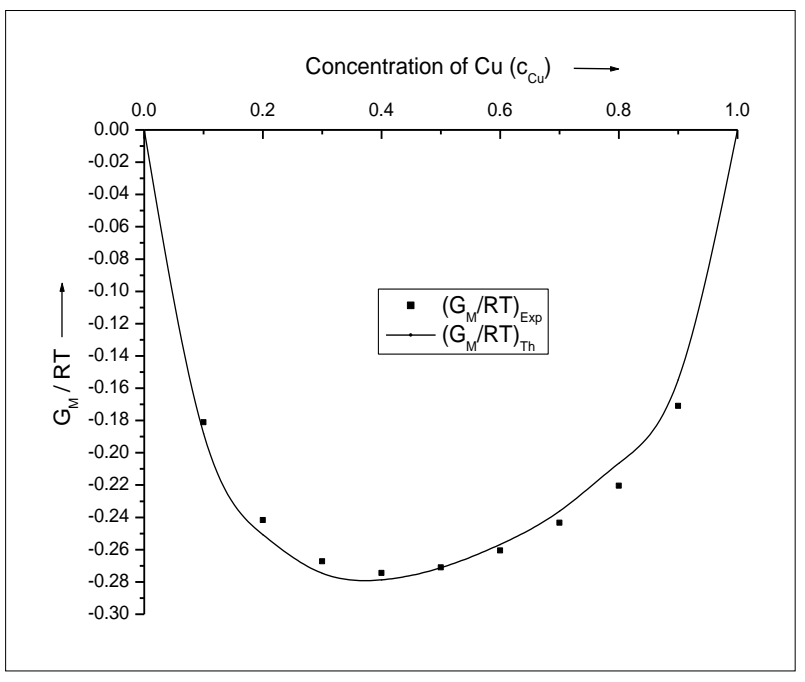

Fig. 1. Graph for $\frac{G_{M}}{R T}$ versus $c_{C u}$ of $C u-P b$ liquid alloys at $1473 \mathrm{~K}$.

Again, the theoretical values of $\ln a_{i}(\mathrm{i} \equiv \mathrm{Cu} ; \mathrm{Pb})$ for $\mathrm{Cu}-\mathrm{Pb}$ liquid alloys at $1473 \mathrm{~K}$ in the entire concentration range have been computed by using expressions (6) and (7) (on taking the fitted values of $\Omega=1.31$ and $\mathrm{W}=1.52)$, while the experimental values of $\ln a_{i}(\mathrm{i} \equiv \mathrm{Cu} ; \mathrm{Pb})$ for $\mathrm{Cu}-\mathrm{Pb}$ liquid alloys at $1473 \mathrm{~K}$ in the entire concentration range have been computed from experimental data (Hultgren et al., 1973). The theoretical and experimental values of $\ln a_{i}(\mathrm{i} \equiv \mathrm{Cu} ; \mathrm{Pb})$ for $\mathrm{Cu}-\mathrm{Pb}$ liquid alloys at $1473 \mathrm{~K}$ in the entire concentration range are compared by plotting their graphs against the concentration of $\mathrm{Cu}$ as shown in figure 2, which are in good agreement.

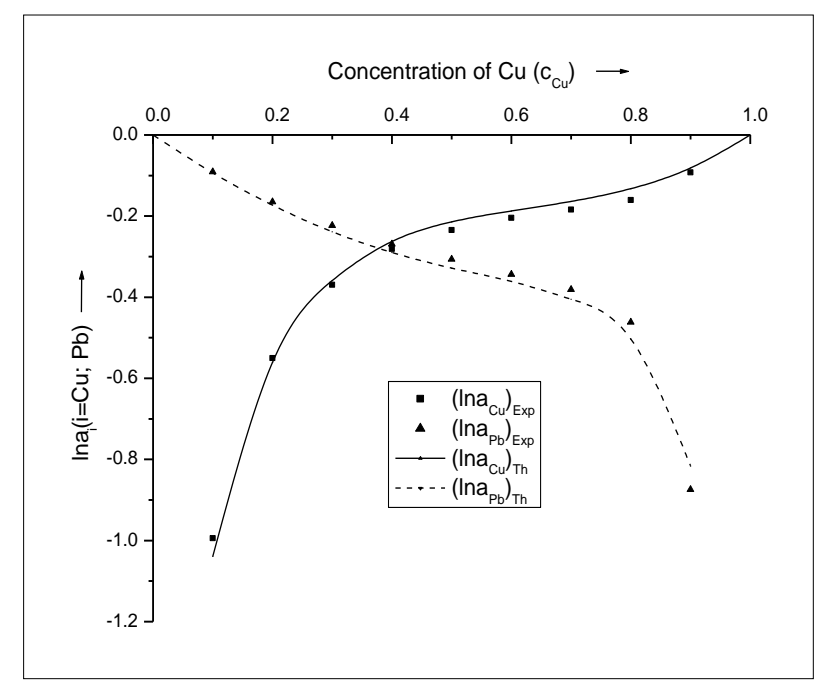

Fig. 2. Graph for $\ln a_{i}(i \equiv C u ; P b)$ versus $c_{C u}$ of $\mathrm{Cu}$-Pb liquid alloys at $1473 \mathrm{~K}$. 
The theoretical values of $S_{c c}(0)$ for $\mathrm{Cu}-\mathrm{Pb}$ liquid alloys at $1473 \mathrm{~K}$ in the entire concentration range have been computed by using the expressions (9) and (10) (on taking $\Omega=1.31, \mathrm{~W}=1.52$ ) while the experimental values of concentration fluctuations in long wave-length limit $\left(S_{c c}(0)\right)$ for $\mathrm{Cu}-\mathrm{Pb}$ liquid alloys at $1473 \mathrm{~K}$ in the entire concentration range have been computed by using the experimental values of activity in expression (11) from the experimental data (Hultgren et al., 1973). The theoretical and experimental values of $S_{c c}(0)$ for $\mathrm{Cu}-\mathrm{Pb}$ liquid alloys at $1473 \mathrm{~K}$ in the entire concentration range are compared by plotting their graphs against the concentration of $\mathrm{Cu}$ as shown in figure 3, which are in good agreement. The experimental value of $S_{c c}(0)$ is maximum at concentration, $\mathrm{c}=0.6$ which is found to be 1.726898 while the theoretical value of $S_{c c}(0)$ is maximum at the same concentration, $\mathrm{c}=0.6$ which is found to be 1.757722 . It is obvious that the concentration fluctuations in long wave-length limit $\left(S_{c c}(0)\right)$ for $\mathrm{Cu}-\mathrm{Pb}$ liquid alloys at $1473 \mathrm{~K}$ in the entire concentration range is always greater than the ideal value of concentration fluctuations $\left(S_{c c}^{i d}(0)\right)$ at each concentration which confirms that the $\mathrm{Cu}-\mathrm{Pb}$ liquid alloys has segregating nature.

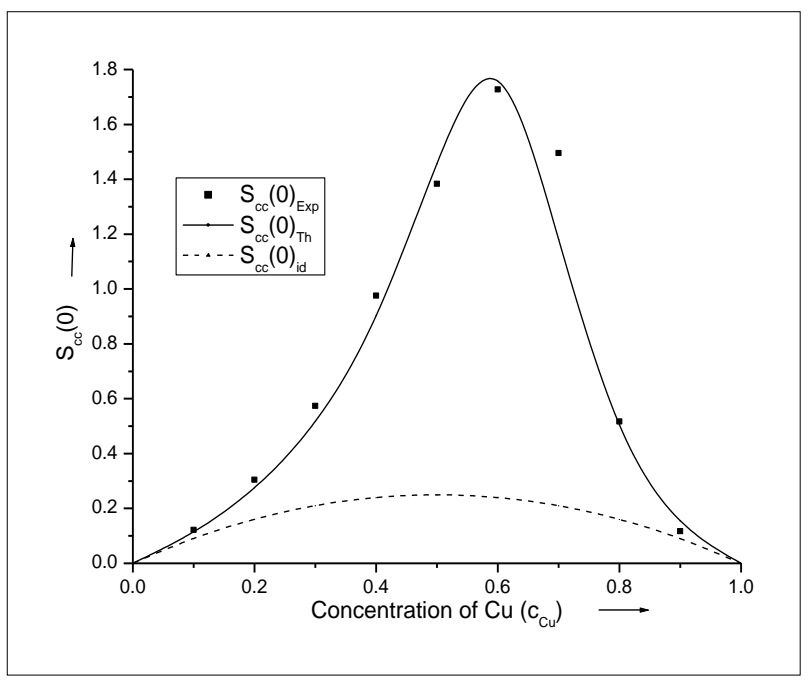

Fig. 3. Graph for $S_{c c}(0)$ versus $C_{C u}$ of $C u$-Pb liquid alloys at $1473 K$.

As represented in expressions (13) and (14), the theoretical values of entropy of mixing $\left(\mathrm{S}_{\mathrm{M}}\right)$ and enthalpy of mixing $\left(\mathrm{H}_{\mathrm{M}}\right)$ for a binary liquid alloys in the entire concentration range can only be determined by knowing the value of temperature derivative of order energy parameter, i.e. $\frac{d W}{d T}$, of the alloys. It's value for $\mathrm{Cu}-\mathrm{Pb}$ binary liquid alloys has been estimated from expressions (13) or (14) to reproduce simultaneously an overall fit for the theoretical and experimental values of entropy of mixing $\left(\mathrm{S}_{\mathrm{M}}\right)$ and heat of mixing $\left(\mathrm{H}_{\mathrm{M}}\right)$ of $\mathrm{Cu}-\mathrm{Pb}$ liquid alloys at $1473 \mathrm{~K}$ in the entire concentration ranging from 0.1 to 0.9 . The best fit value of $\frac{d W}{d T}$ for $\mathrm{Cu}-\mathrm{Pb}$ liquid alloys is found to be $-0.001325 \mathrm{~K}^{-1}$. The theoretical values of $S_{M} / R$ for $\mathrm{Cu}-\mathrm{Pb}$ liquid alloys at $1473 \mathrm{~K}$ in the entire concentration range have been computed by using the expressions (13) (on taking $\Omega=1.31, \mathrm{~W}=1.52$ and $\frac{d W}{d T}=-$ $0.001325 \mathrm{~K}^{-1}$ ) while the experimental values of $\mathrm{S}_{\mathrm{M}} / \mathrm{R}$ for $\mathrm{Cu}-\mathrm{Pb}$ liquid alloys at $1473 \mathrm{~K}$ in the entire concentration range have been computed from the experimental data (Hultgren et al., 1973). The theoretical and experimental values of $\mathrm{S}_{\mathrm{M}} / \mathrm{R}$ for $\mathrm{Cu}$ $\mathrm{Pb}$ liquid alloys at $1473 \mathrm{~K}$ in the entire concentration range are compared by plotting their graphs against the concentration of $\mathrm{Cu}$ as shown in figure 4 , which are in excellent agreement. The experimental value of $S_{M} / R$ at $1473 \mathrm{~K}$ is maximum at the concentration, $\mathrm{c}=0.5$, which is found to be 0.820686 while the theoretical value of $S_{M} / R$ at $1473 \mathrm{~K}$ is maximum at the same concentration, $\mathrm{c}=$ 0.5 which is found to be 0.824649 .

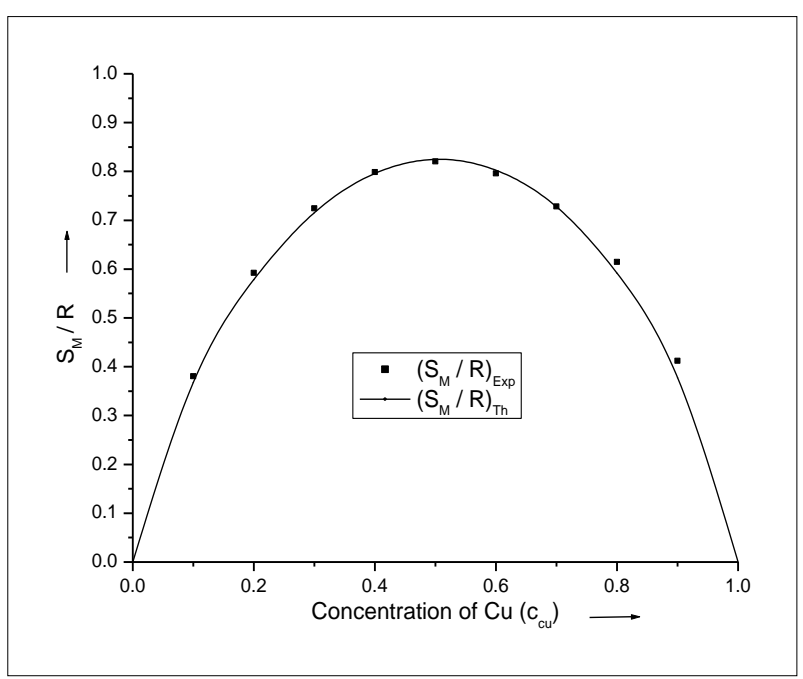

\section{Fig. 4. Graph for $\frac{S_{M}}{R}$ versus $c_{C u}$ of Cu-Pb liquid alloys at $1473 \mathrm{~K}$.}

Further, the theoretical values of $\mathrm{H}_{\mathrm{M}} / \mathrm{RT}$ (on taking $\Omega=1.31, \mathrm{~W}=1.52$ and $\left.\frac{d W}{d T}=-0.001325 \mathrm{~K}^{-1}\right)$ as computed by using expression (14) and experimental values of $\mathrm{H}_{\mathrm{M}} / \mathrm{RT}$ from experimental data (Hultgren et 
al., 1973) for $\mathrm{Cu}-\mathrm{Pb}$ liquid alloys at $1473 \mathrm{~K}$ in the entire concentration range are compared by plotting their graphs against the concentration of $\mathrm{Cu}$ as shown in figure 5, which are in excellent agreement. The experimental value of $\mathrm{H}_{\mathrm{M}} / \mathrm{RT}$ at $1473 \mathrm{~K}$ is maximum at the concentration, $\mathrm{c}=0.5$, which is found to be 0.549291 and the theoretical value of $\mathrm{H}_{\mathrm{M}} / \mathrm{RT}$ at $1473 \mathrm{~K}$ is maximum at the same concentration, $\mathrm{c}=0.5$ which is found to be 0.553411 .

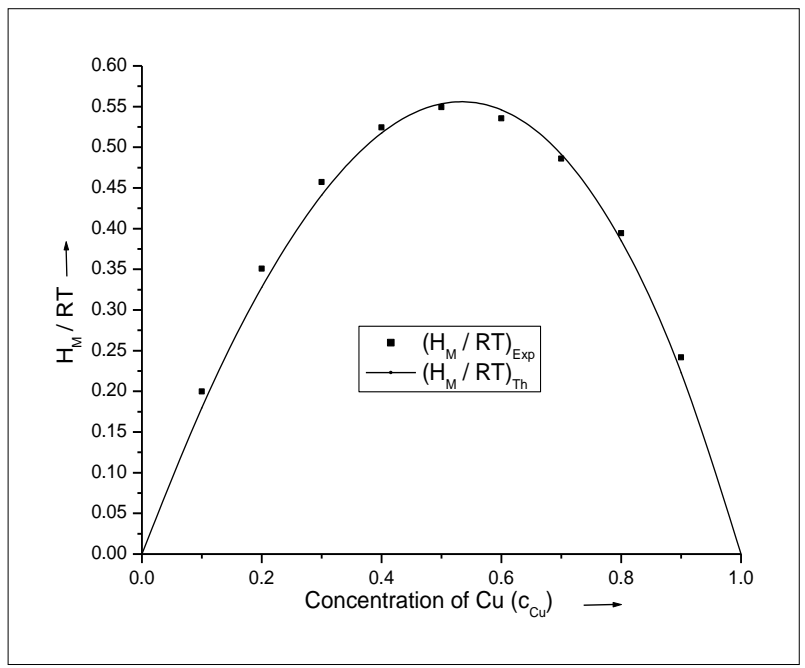

Fig. 5. Graph for $\frac{H_{M}}{R T}$ versus $c_{C u}$ of $\mathrm{Cu}-\mathrm{Pb}$ liquid alloys at $1473 \mathrm{~K}$.
From the above results and discussions, it is obvious that the theoretical values of free energy of mixing $\left(\mathrm{G}_{\mathrm{M}}\right)$, activity $\left(\mathrm{a}_{\mathrm{i}}\right)$ of both the constituents, entropy of mixing $\left(\mathrm{S}_{\mathrm{M}}\right)$, heat of mixing $\left(\mathrm{H}_{\mathrm{M}}\right)$ and concentration fluctuations in long wave-length limit $\left(\mathrm{S}_{\mathrm{cc}}(0)\right)$ of $\mathrm{Cu}-\mathrm{Pb}$ liquid alloys at $1473 \mathrm{~K}$ as calculated in this paper and their corresponding experimental values as obtained from experimental data (Hultgren et al., 1973) are in excellent agreement so that the theoretical model that we use in this research work successfully explain the above thermodynamic properties and concentration fluctuations of $\mathrm{Cu}-\mathrm{Pb}$ liquid alloys. Thus, the above estimated fitted values of size ratio $(\Omega)=1.31$, order energy parameter $(\mathrm{W})=1.52$ and temperature derivative of $\mathrm{W}\left(\frac{d W}{d T}\right)=-0.001325 \mathrm{~K}^{-1}$ for $\mathrm{Cu}-\mathrm{Pb}$ liquid alloys at $1473 \mathrm{~K}$ would be used in next section for optimization procedure to predict the concentration fluctuations in long wave-length limit of $\mathrm{Cu}-\mathrm{Pb}$ liquid alloys at different temperatures.

By using the best fit value of $\frac{\mathrm{dW}}{\mathrm{dT}}$, i.e. $-0.001325 \mathrm{~K}^{-1}$ and $\mathrm{W}(\mathrm{T})$ at the given temperature $\mathrm{T}=1473 \mathrm{~K}$, i.e. 1.52 for $\mathrm{Cu}-\mathrm{Pb}$ liquid alloys in equation (19), the values of $\mathrm{W}\left(\mathrm{T}_{\mathrm{k}}\right)$ at temperatures $\mathrm{T}_{\mathrm{k}}=1373 \mathrm{~K}, 1573 \mathrm{~K}, 1673 \mathrm{~K}$ are calculated and tabulated in Table 1.

Table 1. Calculated values of order energy parameter $(\mathrm{W})$ at different temperature for $\mathrm{Cu}-\mathrm{Pb}$ liquid alloys.

\begin{tabular}{|c|c|}
\hline Temperature $\left(\mathbf{T}_{\mathbf{k}}\right)$ in $\mathbf{K}$ & Order Energy Parameter, $\mathbf{W}\left(\mathbf{T}_{\mathbf{k}}\right)$ \\
\hline 1473 & 1.5200 \\
\hline 1373 & 1.6525 \\
\hline 1573 & 1.3875 \\
\hline 1673 & 1.2550 \\
\hline
\end{tabular}

The values of free energy of mixing $\left(\mathrm{G}_{\mathrm{M}}\right)$ for $\mathrm{Cu}-\mathrm{Pb}$ liquid alloys at different temperatures (i.e. $1473 \mathrm{~K}$, $1373 \mathrm{~K}, 1573 \mathrm{~K}$ and $1673 \mathrm{~K}$ ) have been calculated by using the corresponding values of $\mathrm{W}$ and $\Omega$ in expression (1) in the entire range of concentration and then they are used to calculate the corresponding excess free energy of mixing $\left(G_{M}^{X S}\right)$ of $\mathrm{Cu}-\mathrm{Pb}$ liquid alloys at different temperature (i.e. at $1473 \mathrm{~K}, 1373 \mathrm{~K}, 1573 \mathrm{~K}$ and $1673 \mathrm{~K}$ ) by using expression (18).

The least-square method has been used to calculate the parameters involved in expression (16) and then the optimized coefficients involved in expression (17) for $\mathrm{Cu}-\mathrm{Pb}$ liquid alloys are computed which are tabulated in the Table 2. 
Table 2. Calculated values of optimized coefficients $A_{l}, B_{l}, C_{l}, D_{l}(l=0$ to 3$)$ for $\mathrm{Cu}-\mathrm{Pb}$ liquid alloys

\begin{tabular}{|l|l|l|l|l|}
\hline Values of $l$ & $\mathrm{~A}_{l}\left(\mathrm{~J} \mathrm{~mol}^{-1}\right)$ & $\mathrm{B}_{l}\left(\mathrm{~J} \mathrm{~mol}^{-1} \mathrm{~K}^{-1}\right)$ & $\mathrm{C}_{l}\left(\mathrm{~J} \mathrm{~mol}^{-1} \mathrm{~K}^{-1}\right)$ & $\mathrm{D}_{l}\left(\mathrm{Jmol}^{-1} \mathrm{~K}^{-2}\right)$ \\
\hline 0 & 0.2091002055 & 32.4331135894 & 0.0002690950 & -0.0124944218 \\
\hline 1 & -0.6663477803 & 4.3726648981 & -0.0008783487 & -0.0016764404 \\
\hline 2 & 0.2331685507 & 0.5887799926 & 0.0003205009 & -0.0002267582 \\
\hline 3 & 1.6039799389 & 0.0638345415 & 0.0021264170 & -0.0000311191 \\
\hline
\end{tabular}

Further, the optimized values of partial excess free energy of mixing of the constituents $\mathrm{X}(\equiv \mathrm{Cu})$ and $\mathrm{Y}(\equiv \mathrm{Pb})$ in $\mathrm{Cu}-\mathrm{Pb}$ liquid alloys are given by $\tilde{G}_{M, X}^{X S}(c, T)=(1-c)^{2} \sum_{l=0}^{m} K_{l}(T)[2 c(l+1)-$ 1] $(2 \mathrm{c}-1)^{l-1}$

and

$\tilde{G}_{M, Y}^{X S}(c, T)=c^{2} \quad \sum_{l=0}^{m} K_{l}(T)[2 c(l+1)-2 l-$ 1] $(2 \mathrm{c}-1)^{l-1}$

The partial excess free energy of mixing of both the constituents $\mathrm{Cu}$ and $\mathrm{Pb}$ involved in $\mathrm{Cu}-\mathrm{Pb}$ liquid alloys at different temperatures (i.e. $1473 \mathrm{~K}, 1373 \mathrm{~K}$, $1573 \mathrm{~K}$ and $1673 \mathrm{~K}$ ) have been calculated separately in the entire concentration range by equations (20) and (21) with the help of optimized coefficients. These optimized values of partial excess free energy of mixing of both the constituents involved in the alloy have also been used to obtain the corresponding optimized values of excess free energy of mixing for $\mathrm{Cu}-\mathrm{Pb}$ liquid alloys at different temperatures in the entire concentration range from the relation

$G_{M}^{X S}(c, T)=c\left\{\tilde{G}_{M, X}^{X S}(c, T)\right\}+(1-c)\left\{\tilde{G}_{M, Y}^{X S}(c, T)\right\}$

Again, the optimized values of activity coefficients $\left(\gamma_{i}\right)$ in the entire concentration range of the component i $(\mathrm{i} \equiv \mathrm{Cu} ; \mathrm{Pb})$ at corresponding temperature have been computed from the relation

$\tilde{G}_{M, i}^{X S}=R T \ln \gamma_{i}$

with $\gamma_{i}=\frac{\mathrm{a}_{\mathrm{i}}}{\mathrm{c}_{\mathrm{i}}}$

where $a_{i}$ and $c_{i}$ be the activity and concentration of the component $\mathrm{i}(\mathrm{i} \equiv \mathrm{Cu}$, or $\mathrm{Pb})$ of $\mathrm{Cu}-\mathrm{Pb}$ liquid alloys at corresponding temperature.
The optimized values of excess free energy of mixing for $\mathrm{Cu}-\mathrm{Pb}$ liquid alloys at different temperatures, $\mathrm{T}=1473 \mathrm{~K}, 1373 \mathrm{~K}, 1573 \mathrm{~K}$ and $1673 \mathrm{~K}$ in the entire concentration range as obtained by putting the optimized values of $\tilde{G}_{M, C u}^{X s}$ and $\tilde{G}_{M, P b}^{X s}$ in expression (22) are compared by plotting their graphs against concentration of $\mathrm{Cu}$ as shown in figure 6.

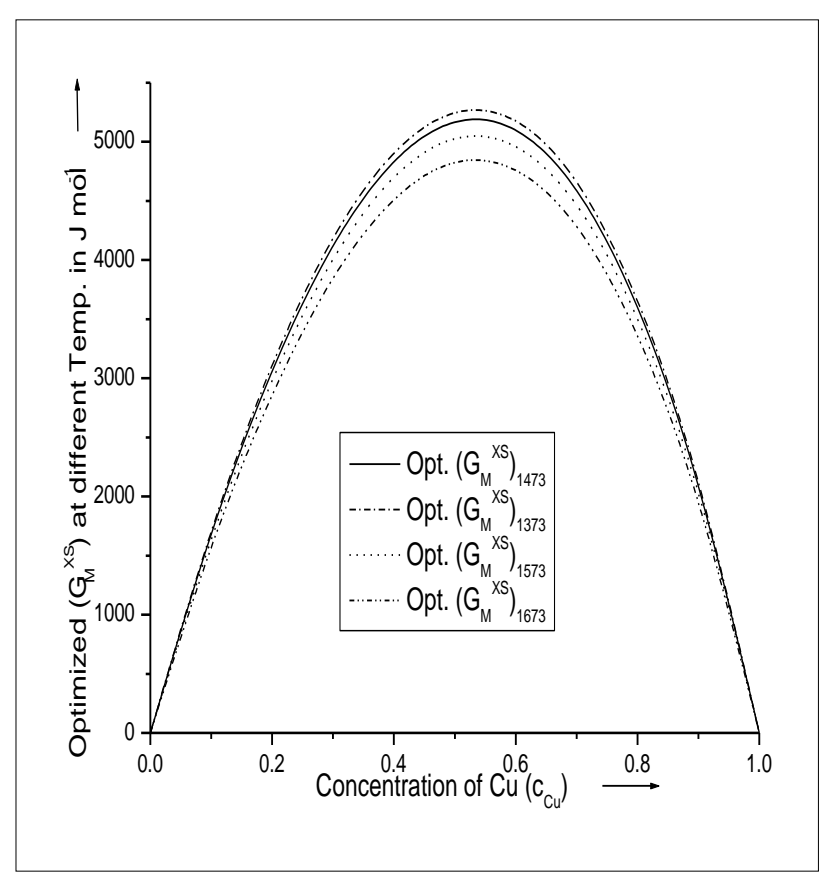

\section{Fig. 6. Graph for Optimized $G_{M}^{X S}$ versus $c_{C u}$ of $\mathrm{Cu}$ - $P b$ liquid alloys at different temperature.}

The natural logarithms of optimized values of activity of the constituent $i$ of $\mathrm{Cu}-\mathrm{Pb}$ liquid alloys at different temperatures, $\mathrm{T}=1473 \mathrm{~K}, 1373 \mathrm{~K}$, $1573 \mathrm{~K}$ and $1673 \mathrm{~K}$ in the entire concentration range as obtained by putting the optimized values of $\widetilde{G}_{M, i}^{X S}$ in expression (23) and $\gamma_{i}$ in expression (24) ( $\mathrm{i} \equiv \mathrm{Cu}$, or $\mathrm{Pb}$ ) are compared by plotting their graphs against concentration of $\mathrm{Cu}$ as shown in figure 7. 


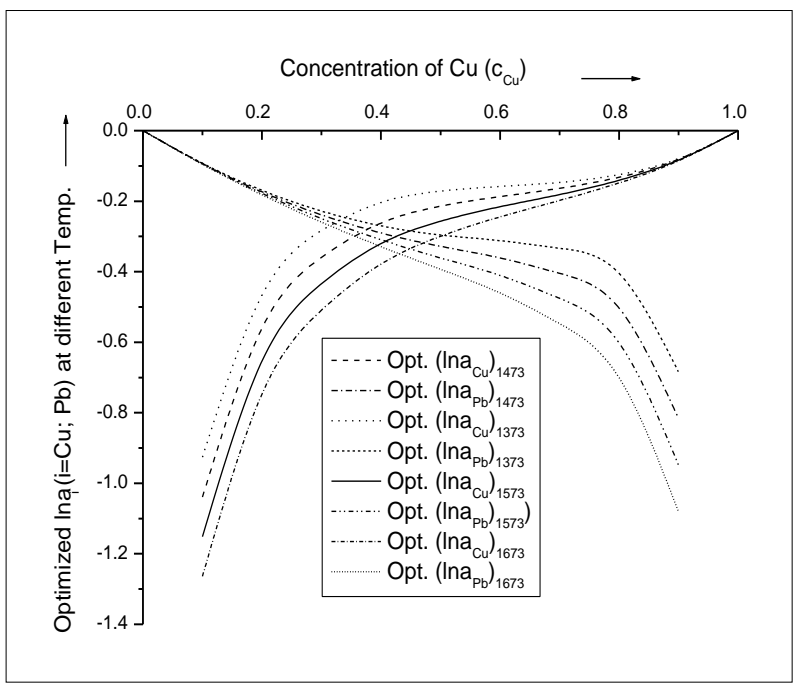

Fig. 7. Graph for Optimized $\ln a_{i}(i \equiv C u ; P b)$ versus $c_{C u}$ of $\mathrm{Cu}-\mathrm{Pb}$ liquid alloys at different temperature.

Finally, the concentration fluctuations in long wave-length limit $\left(S_{c c}(0)\right)$ of $\mathrm{Cu}-\mathrm{Pb}$ liquid alloys at different temperatures, $\mathrm{T}=1473 \mathrm{~K}, 1373 \mathrm{~K}, 1573 \mathrm{~K}$ and $1673 \mathrm{~K}$ in the entire concentration range as obtained by putting the optimized values of activity $\left(a_{i}\right)$ in expression (11) with the help of optimized values of $\tilde{G}_{M, i}^{X S}$ and $\gamma_{i}(\mathrm{i} \equiv C u$, or $P b)$ are compared by plotting their graphs against concentration of $\mathrm{Cu}$ as shown in Fig. 8.

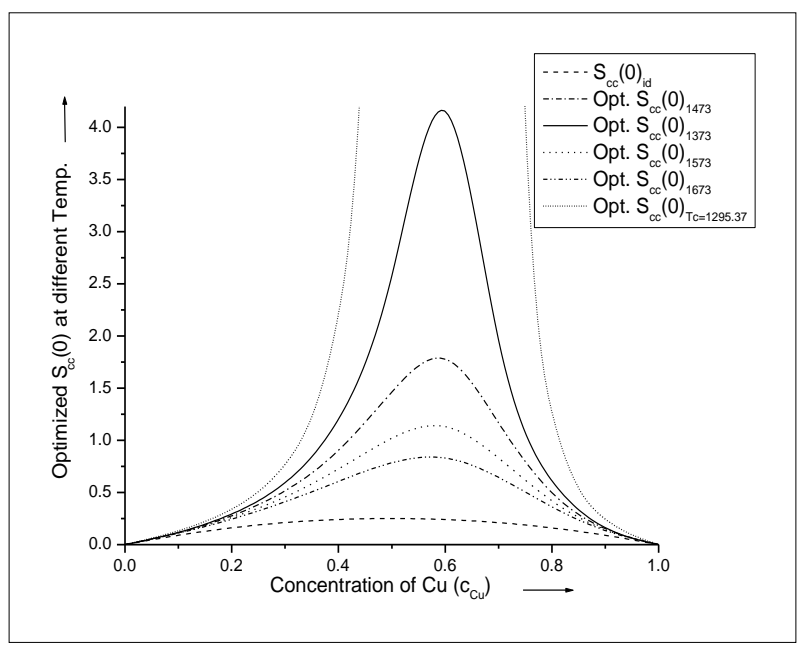

\section{Fig. 8. Graph for Optimized $S_{c c}(0)$ versus $c_{C u}$ of $\mathrm{Cu}-\mathrm{Pb}$ liquid alloys at different temperature.}

From the comparative study of optimized values of concentration fluctuations in long wavelength limit of $\mathrm{Cu}-\mathrm{Pb}$ liquid alloys at different temperatures, it is concluded that the concentration fluctuations in long wavelength limit of the alloy decreases as the temperature increases and shift towards the ideal value of concentration fluctuations $\left(S_{c c}^{i d}(0)\right)$ at each concentration on increasing the temperature but remains greater than the ideal value of concentration fluctuations which indicates that the $\mathrm{Cu}-\mathrm{Pb}$ liquid alloy has segregating nature in the entire concentration range but the segregating nature decreases as the temperature increases. It is also noted that the critical temperature $\left(\mathrm{T}_{\mathrm{c}}\right)$ for $\mathrm{Cu}-$ $\mathrm{Pb}$ liquid alloy is $1295.37 \mathrm{~K}$ and the critical concentration $\left(\mathrm{C}_{\mathrm{c}}\right)$ is 0.6 .

\section{CONCLUSION}

The following conclusions may be drawn from the study of this theoretical assessment in various properties of $\mathrm{Cu}-\mathrm{Pb}$ liquid alloys:

- The mixing properties of the $\mathrm{Cu}-\mathrm{Pb}$ liquid alloys are very sensitive on the order energy parameter (W) of the alloys which has a fixed value at a particular temperature but it is temperature dependent. The values of $\mathrm{W}$ in the temperature range $1373 \mathrm{~K}$ to $1673 \mathrm{~K}$ of $\mathrm{Cu}-\mathrm{Pb}$ liquid alloys are in positive and its value decreases as the temperature increases because of negative value of temperature derivative of $\mathrm{W}$ in $\mathrm{Cu}-\mathrm{Pb}$ liquid alloys.

- The values of concentration fluctuations in long wavelength limit of $\mathrm{Cu}-\mathrm{Pb}$ liquid alloys decreases as the temperature increases at each concentration and shifts towards the ideal value of concentration fluctuations as the temperature increases which indicates that the segregating nature of the alloy decreases as the temperature increases.

- The decrease in the value of excess free energy of mixing in $\mathrm{Cu}-\mathrm{Pb}$ liquid alloys with the increase in temperature of the alloys indicates that the bonding strength between unlike atoms present in the alloys increases as temperature increases.

- The critical temperature $\left(\mathrm{T}_{\mathrm{c}}\right)$ for $\mathrm{Cu}-\mathrm{Pb}$ liquid alloy was found to be $1295.37 \mathrm{~K}$ and the critical concentration $\left(\mathrm{C}_{\mathrm{c}}\right)$ was found to be 0.6 .

- The free energy of mixing $\left(\mathrm{G}_{\mathrm{M}}\right)$, entropy of mixing $\left(\mathrm{S}_{\mathrm{M}}\right)$, heat of mixing $\left(\mathrm{H}_{\mathrm{M}}\right)$ and concentration fluctuations in long wavelength limit $\left(S_{c c}(0)\right)$ of $\mathrm{Cu}-\mathrm{Pb}$ liquid alloy are symmetrical or very close to it at the equi-atomic composition of its 
constituents (i.e. $\mathrm{c}=0.5$ ) so that this alloy is regular symmetric alloy.

\section{REFERENCES}

Adhikari, D.; Jha, I. S. and Singh, B. P. (2010). Structural asymmetry in liquid $\mathrm{Fe}-\mathrm{Si}$ alloys. Philosophical Magazine, 90 (20): 2687 2694.

Akinlade, O.; Singh, R. N. and Sommer, F. (2000). Thermodynamics of liquid Al-Fe alloys. Journal of Alloys and Compounds, 299: 163 168.

Alonso, J. A. and March, N. H. (1982). Concentration fluctuations in simple metallic liquid alloys. Physics $B+C 114$ (1): 67-70.

Awe, O. E.; Akinwale, I.; Imeh, J. and Out, J. (2010). Calculation of experimental concentration-concentration fluctuations of liquid binary alloys using experimental free energy of mixing and experimental activities. Physics and Chemistry of Liquids, 48 (2): 243-256.

Bhatia, A. B. and Singh, R. N. (1982). Thermodynamic Properties of Compound Forming Molten Alloys in a Weak Interaction Approximation. Physics and Chemistry of Liquids, 11 (4): 343-351.

Bhatia, A. B. and Thornton, D. E. (1971). Structural Aspects of the Electrical Resistivity of Binary Alloys. II. Long-Wavelength Limit of the Structure Factors for a Solid Alloy. Physical Review B, 4 (8): 2325-2328.

Buchanan, V. E.; Molian, P. A.; Sudarshan, T. S.; and Akers, A. (1991). Frictional behavior of non-equilibrium $\mathrm{Cu}-\mathrm{Pb}$ alloys. Wear, 146: 241-256.

Cui H. et al. (2007). Effect of $\mathrm{Cr}$ addition on microstructure and wear resistance of hypomonotectic $\mathrm{Cu}-\mathrm{Pb}$ alloy. Material Science and Engineering: A, 448: 49-55.

Flory, P. J. (1942). Thermodynamics of High Polymer Solutions. Journal of Chemical Physics, 10 (1): 51.

Guggenheim, E. A. (1952). Mixtures. Oxford University Press. London.
Hultgren, R.; Desai, P. D.; Hawkins, D. T.; Gleiser, M.; Kelley, K. K. (1973). Selected Values of the Thermodynamic Properties of Binary Alloys. ASM Metals Park, Ohio, pp. 1013.

Jha, I. S.; Singh, B. P. and Koirala, I. (2014). Theoretical assessment on segregating nature of liquid In-Tl alloys. Journal of Non Crystalline Solids, 398-399: 26-31.

Koirala, I.; Jha, I. S.; Singh, B. P. and Adhikari, D. (2013 a). The thermodynamic, transport and surface properties in $\mathrm{In}-\mathrm{Pb}$ liquid alloys. Physica B, 42: 49-56.

Koirala, R. P.; Singh, B. P.; Jha, I. S., and Adhikari, D. (2013 b). Thermodynamic, Structural and surface properties of liquid $\mathrm{Cd}-\mathrm{Zn}$ Alloys. Journal of Molecular Liquids, 179: 60-66.

Mudry, S. (1996). Structure of Liquid Cu-Pb Alloys. Physics and Chemistry of Liquids, 32 (4): 239-244.

Prasad, L. C. and Singh, R. N. (1989). A Quasilattice Model for the Thermodynamic Properties of Au-Zn Liquid Alloys. Physics Chemistry Liquid An International Journal, 22: $37-41$.

Shrestha, G. K.; Singh, B. K.; Jha, I. S.; Singh, B. P. and Adhikari, D. (2017). Optimization method for the study of the properties of AlSn binary liquid alloys. Physica B: Condensed Matter, 514: 1-7.

Singh, B. P.; Singh, B. K.; Jha, I. S.; Shrestha, G. K. and Koirala, I. (2014 a). Study of size mismatches effect on transport properties in $\mathrm{Cu}-\mathrm{Sb}$ and $\mathrm{Cu}-\mathrm{Sn}$ liquid alloys. BIBECHANA 12: 96-103.

Singh, B. P.; Koirala, I.; Jha, I. S. and Adhikari, D. $(2014 \mathrm{~b})$. The segregating nature of $\mathrm{Cd}-\mathrm{Pb}$ liquid binary alloys. Physics and Chemistry of Liquids, 52 (4): 457-470.

Singh, R. N. and Sommer, F. (1997). Segregation and immiscibility in liquid binary alloys. Reports on Progress in Physics, 60 (1): 57-150.

Young, W. H. (1992). Structural and thermodynamic properties of NFE liquid metals and binary alloys. Reports on Progress in Physics, 55 (10): 1769-1853. 